\title{
IMPLEMENTASI PROGRAM INDONESIA PINTAR PADA SMPN 3 BANJARBARU KECAMATAN CEMPAKA KOTA BANJARBARU
}

\author{
Tamliha Harun \\ FIA, Universitas Achmad Yani Banjarmasin \\ Email : tamlihaharun@yahoo.co.id
}

\begin{abstract}
The purpose of this research is to find out how the implementation of the Smart Indonesia Program (PIP) at SMPN 3 Banjarbaru, Cempaka Subdistrict, Banjarbaru City, is it in accordance with the Regulation of the Director General of Education of the Ministry of Education and Culture Number: 1881 / D / BP / 2019 concerning Guidelines for Implementing the Smart Indonesia Program at the Basic Education level. This research is a descriptive study, with data collection techniques interview, observation, and documentation, then the results are analyzed qualitatively. The results of this study indicate that: a. Implementation of the Smart Indonesia Program (PIH), through the Smart Indonesia Card (KIP) at SMPN 3 Banjarbaru has been running well and effectively, in accordance with applicable regulations; $b$. The number of students receiving assistance from the Smart Indonesia Program through the Smart Indonesia Card at SMPN 3 Banjarbaru was 228 students. However, there are some people who actually no longer meet the requirements, because the income of the parents / guardians of the students concerned has increased from before. KIP recipient students, the process of recapitulation, verification and input of student KIP recipient student data to Dapodik, until the disbursement and use of KIP funds by recipient students; $d$. The Smart Indonesia Program (PIH), through the Smart Indonesia Card (KIP) at SMPN 3 Banjarbaru, is very beneficial for students from poor or underprivileged families, so that the number of students dropping out of school can be reduced; e. However, there were still some students who received KIP or their guardians who did not understand the use of KIP funds, so they were used to finance expenses outside the context of their educational / school needs.
\end{abstract}

Keyword: Implementation, PIP, SMPN 3 Banjarbaru.

\section{PENDAHULUAN}

Menurut Undang - Undang Dasar 1945 pasal 31 ayat (1) yang berbunyi setiap warga Negara berhak memdapatkan pendidikan. Itu artinya pendidikan adalah hak mutlak bagi setiap warga Negara yang berusia 6 tahun sampai dengan 18 tahun untuk mengenyam pendidikan, dari pendidikan dasar sampai dengan perguruan tinggi tanpa memandang status sosial seseorang. Selanjutnya pasal 31 ayat (2) nya menyatakan, bahwa setiap warga negara wajib mengikuti pendidikan dasar dan pemerintah wajib membiayainya. Berarti setiap anak usia sekolah pendidikan dasar ( SD - SMP) biaya pendidikannya ditanggung atau dijamin oleh pemerintah alias gratis.

Salah satu bentuk tanggung jawab pemerintah tersebut di Implementasikan melalui sebuah kebijakan/Program Indonesia Pintar yang bertujuan untuk membantu biaya pendidikan kepada anak keluarga yang kurang mampu. Walau pun setiap warga negara mempunyai hak mutlak untuk mendapatkan pendidikan, dan semua orang mengakui dan menyadari bahwa pendidikan itu sangat penting, namun tidak semua warga negara atau anggota masyarakat dapat mengenyam pendidikan. Permasalahan tersebut terkendala oleh biaya pendidikan yang cukup tinggi dan merupakan beban berat bagi sebagian anggota masyarakat. Sehingga ada sebagian anggota masyarakat (anak usia sekolah) lebih memilih bekerja untuk memenuhi kebutuhannya sehari-hari dari pada mengikuti pendidikan di sekolah.Dampaknya adalah meningkatnya anak putus sekolah.

Untuk mengatasi hal tersebut pemerintah melalui Intruksi Presiden Republik Indonesia Nomor 7 Tahun 2014 Tentang Pelaksanaan Keluarga Sejahtera, Program Indonesia Pintar, dan Program Indonesia Sehat untuk membangun keluarga produktif. Inpres ini di tindak lanjuti Kementrian Pendidikan dan Kebudayaan dengan Peraturan Nomor : 1881 / D / BP / 2019 Tentang 
Petunjuk Pelaksanaan Program Indonesia Pintar ( PIP ) pada jenjang Pendidikan Dasar dan Menengah.

Program Indonesia Pintar melalui Kementrian Pendidikan dan Kebudayaan mengeluarkan Kartu Indonesia Pintar sebagai program bantuan siswa miskin atau kurang mampu yang mencakup siswa SD/MI, SMP/MTs, SMA/SMK/MA dan siswa /warga yang menempuh pendidikan di Pusat Kegiatan Belajar Mengajar ( PKBM ). Program Indonesia Pintar itu sendiri diperuntukan bagi keluarga kurang mampu yang memiliki anak usia 6 s/d 18 tahun agar dapat menyekolahkan anaknya secara gratis. Program Indonesia Pintar ini diberikan dalam bentuk uang tunai secara regular oleh pemerintah kepada siswa yang memiliki Kartu Indonesia Pintar.

Sekolah Menengah Pertama Negeri (SMPN) 3 Banjarbaru merupakan salah satu sekolah yang ikut terlibat dalam mengimplementasikan Program Indonesia Pintar sejak tahun 2015. Pada Tahun 2019 di SMPN 3 Banjarbaru terdapat 228 siswa miskin sebagai penerima bantuan Kartu Indonesia Pintar. Masing - masing siswa di sekolah ini menerima bantuan sebesar Rp. 750.000,- / semester. Siswa-siswa tersebut mendapatkan Kartu Indonesia Pintar berdasarkan dari pemegang Kartu Keluarga Sejahtera ( KKS ) dan Program Keluarga Harapan ( $\mathrm{PKH}$ ) yang dikirim dari Pemerintah Pusat ke Kantor Kelurahan sampai ke RT-RT, yang selanjutnya menyampaikan kepada keluarga siswa yang berhak menerimanya. Menurut hasil penjajakan dan pengamatan sementara yang peneliti lakukan di SMPN Negeri 3 Banjarbaru, ada beberapa indikasi yang menunjukkan bahwa pemberian Kartu Indonesia Pintar kurang tepat sasaran, kurang afektifnya penggunaan dana KIP oleh siswa penerima, dan lemahnya kewenangan pengawasan sekolah terhadap penggunaan dana KIP oleh siswa penerima.

Berdasarkan uraian di atas peneleti tertarik untuk melakukan penelitian lebih lanjut tentang bagaimana implementasi Program Indonesia Pintar (PIP) pada SMP Negeri 3 Banjarbaru Kecamatan Cempaka Kota Banjarbaru, Berdasarkan Peraturan Direktur Jenderal Pendidikan Dasar dan Menengah Kementerian Pendidikan dan Kebudayaan Nomor : 1881/D/BP/2019 tentang Petunjuk Pelaksanaan Program Indonesia Pintar pada Jenjang Pendidikan Dasar dan Menengah.

\section{TINJAUAN PUSTAKA Konsep Kebijakan Publik}

Kebijakan publik adalah serangkaian tindakan / keputusan yang dibuat oleh Negara atau pemerintah yang sifatnya mengikat/ memaksa secara sah kepada masyarakat yang dilaksankan untuk mencapai tujuan atau kepentingan publik/masyarakat. Secara umum kebijakan publik adalah suatu proses pembuatan kebijakan oleh suatu pemerintah atau pemegang kekuasaan yang berdampak kepada masyarakat luas.

Menurut M. Irfan Islamy ( 1999 ) Kebijakan public adalah serangkaian tindakan yang dipilih dan dialokasikan secara sah oleh pemerintah /Negara kepada seluruh anggota masyarakat yang mempunyai tujuan tertentu demi kepentingan publik. Selanjutnya, Riant Nugroho (2011) mengatakan bahwa kebijakan publik adalah setiap keputusan yang dibuat oleh negara, sebagai strategi untuk merealisasikan tujuan negara. Lebih lanjut, Lembaga Administrasi Negara (1997) menggariskan bahwa kebijakan pada dasarnya merupakan ketentuan-ketentuan yang harus dijadikan pedoman, pegangan, atau petunjuk bagi setiap usaha dan kegiatan aparatur pemerintah, sehingga tercapai kelancaran dan keterpaduan dalam upaya mencapai tujuan. Lebih tegas lagi dalam Permenneg PAN Nomor : PER/04/M.PAN/4/2007, tentang Pedoman Umum Formulasi, implementasi, Evaluasi Kinerja, dan Revisi Kebijakan Publik di Lingkungan Lembaga Pemerintah Pusat dan Daerah, bahwa kebijakan publik adalah keputusan yang dibuat oleh pemerintah atau lembaga pemerintahan untuk mengatasi masalah tertentu, untuk melakukan kegiatan tertentu atau untuk mencapai tujuan tertentu yang berkenaan dengan kepentingan dan manfaat orang banyak.

Berdasarkan beberapa batasan pengertian kebijakan publik yang di atas dapat di simpulkan bahwa kebijakan publik itu pada prinsipnya adalah suatu keputusan negara atau pemerintah yang berisi serangkaian kegiatan/strategi yang dipilih untuk melakukan sesuatu atau tidak melakukan sesuatu, keputusan itu bersifat mengikat/memaksa secara sah kepada publik / masyarakat yang ingin diikat, keputusan itu dilaksanakan untuk mencapai tujuan atau memecahkan masalah tertentu, dan ysng paling penting, keputusan itu ditujukan untuk kepentingan public atau masyarakat. 


\section{Kebijakan Program Indonesia Pintar}

Kebijakan/Program Indonesia Pintar (PIP) merupakan salah satu bentuk kebijakan pendidikan. Kebijakan pendidikan merupakan kebijakan publik di bidang pendidikan. Menurut $\mathrm{H}$. A. R Tilaar \& Riant Nugroho (Rawita, 2010), Kebijakan pendidikan adalah keseluruhan proses dan hasil perumusan langkah - langkah strategis pendidikan yang dijabarkan dari visi, misi pendidikan dalam suatu masyarakat untuk kurun waktu tertentu. Sedangkan menurut Carter V. Good (Rawita, 2010) "kebijakan pendidikan sebagai suatu pertimbangan yang didasarkan atas system nilai dan beberapa penilaian terhadap factor-faktor yang bersifat situasional, pertimbangan ini yang dijadikan sebagai dasar untuk mengoprasikan pendidikan yang bersifat melembaga ; pertimbangan tersebut merupakan perencanaan umum yang dijadikan sebagai pedoman utuk mengambil keputusan, agar tujuan yang bersifat melembaga bisa tercapai. Bedasarkan pendapat-pendapat tersebut di atas dapat diambil kesimpulan bahwa kebijakan pendidikan dibuat untuk menjadi pedoman dalam bertindak, dalam melaksanakan kegiatan-kegiatan pendidikan atau organisasi pendidikan (sekolah) baik yang dilaksanakan oleh pemerintah maupun masyarakat untuk mencapai tujuan yang telah di tetapkan. Dengan kata lain, kebijakan pendidikan merupakan garis umum untuk bertindak bagi pengambilan keputusan pada setiap jenjang pendidikan.

Peraturan Menteri Pendidikan dan Kebudayaan Republik Indonesia Nomor 19 Tahun 2016 Tentang Program Indonesia Pintar merupakan salah satu kebijakan pendidikan sebagai bentuk bantuan pemerintah untuk siswa kurang mampu / miskin dengan harapan mengurangi anak putus sekolah. Program Indonesia Pintar melalui Kartu Indonesia Pintar ( KIP ) menurut Tim Nasional Percepatan Penanggulangan Kemiskinan ( TNP2K ) adalah pemberian bantuan tunai pendidikan kepada seluruh anak usia sekolah ( 6-21 tahun ) yang berasal dari keluarga yang mempunyai Kartu Keluarga Sejahtera (KKS) atau yang memenuhi kreteria yang sudah ditetapkan. Kartu Indonesia Pintar juga sebagai lanjutan dari program bantuan siswa miskin (BSM) sebelumnya.

\section{Pengelolaan Kartu Indonesia Pintar (KIP)}

Pengelolaan Kartu Indonesia Pintar sudah diatur dalam peraturan direktur jendral pendidikan dasar dan menengah Nomor : 1881 / D / BP / 2019 tentang petunjuk pelaksanaan program Indonesia pintar pada jenjang pendidikan dasar dan menengah. Program Indonesia Pintar (PIP) diharapkan mampu menjamin peserta didik dapat melanjutkan pendidikan sampai tamat pendidikan menengah, dan menarik perserta didik putus sekolah atau tidak melanjutkan pendidikan agar kembali mendapatkan layanan pendidikan. Program Indonesia Pintar dilaksanakan melalui Dinas Pendidikan Provinsi, Dinas Pendidikan Kabupaten /Kota, dan satuan pendidikan. Kementrian Pendidikan dan Kebudayaan menyediakan Kartu Indonesia Pintar ( KIP ) berdasarkan Data terpadu (BDT) yang dikeluarkan oleh Tim Nasional Percepatan Penangulangan kemiskinan (TNP2K).

Pemanfaatan dana program Indonesia pintar sesuai dengan peraturan direktur jendral pendidikan dasar dan menengah Nomor : 1881 / D / BP / 2019 tentang petunjuk pelaksanaan program Indonesia pintar pada jenjang pendidikan dasar dan menengah yaitu : a. Membeli buku dan alat tulis, b. Membeli pakaian seragam dan perlengkapan sekolah, c. Biaya transportasi peserta didik ke sekolah, d. Uang saku peserta didik, e. Biaya kursus/les tambahan dan/atau, f. Biaya praktik tambahan peserta didik.

Sedangkan sasaran Program Indonesia Pintar adalah : a. Penerima BSM 2014 dan pemegang KPS, b. Anak dari keluarga yang memiliki KPS/KKS/KIP yang belum menerima bantuan BSM 2014, c. Anak dari keluarga peserta program keluarga harapan (PKH) non KPS, d. Anak yang berstatus yatim piatu/piatu dari panti sosial, e. Anak yang terkena dampak bencana alam, f. Anak dari kelurga miskin / rentan yang terancam putus sekolah atau anak dengan pertimbangan khusus lainya seperti : kelainan fisik, korban musibah, dari orang tua PHK, di daerah konflik, kelurga terpidana, berada di LAPAS.

Adapun besaran dana yang di berikan pada Program Indonesia Pintar dengan Kartu Indonesia Pintar sebagai bukti identitas peserta yang mendapatkan dana bantuan di lihat dari masing - masing jenjang pendidikan :

a. Siswa Sekolah Dasar / Madrasah Ibtidaiyah / Paket A diberikan dana Rp. 225.000,/semester ( Rp. 450.000,- / tahun )

b. Tingkat Sekolah Menengah Pertama / Madrasyah Tsanawiyah / paket B diberikan dana Rp. 375.000,- / semester (Rp. 750.000,/tahun) 
c. Tingkat Sekolah Menengah Atas / Sekolah Menengah Kejuruan / Madrasyah Aliah / Paket C diberikan dana Rp. 500.000,- / semester ( Rp. 1.000.000,-/tahun )

d. Bagi peserta kursus selama mengikuti kursus terstandar dalam satu periode kursus dalam satu tahun diberikan dana Rp. 500.000,/semester

( $1.000 .000,-$ / tahun )

\section{Mekanisme Penyaluran Kartu Indonesia Pintar (KIP)}

Mekanisme penetapan dan penyaluran KIP dapat dilakukan dengan ketentuan, sebagai berikut

a. Penerima KIP harus terdaftar sebagai peserta didik di lembaga pendidikan formal maupun non formal.

b. KIP harus terdaftar di data pokok pendidikan (dapodik) lembaga pendidikan penetapan penerima KIP dilaksanakan melalui :

1) Direktorat teknis menerima usulan calon siswa penerima KIP dari dinas pendidikan kabupaten/kota/pemangku kepentingan.

2) Direktorat teknis menetapkan siswa penerima KIP yang berasal dari usulan sekolah yang telah disahkan oleh dinas pendidikan kabupaten/kota.

3) Untuk peserta paket $\mathrm{A} / \mathrm{B} / \mathrm{C}$, penetapan penerima KIP dilakukan oleh Direktorat PSD, PSMP, PSMA setelah menerima surat keputusan penetapan penerima KIP dari Direktorat Pembinaan Pendidikan Masyarakat, Ditjen PAUDNI Kemendikbud.

4) Untuk peserta balai latihan kerja penetapan penerima KIPdilakukan oleh Direktorat Pembinaan SMK setelah menerima surat keputusan penetapan penerima KIP dari Direktorat Bina Lembaga dan Sarana Pelatihan Kerja

Mekanisme penyaluran dana BSM/KIP disalurkan langsung ke peserta didik penerima, adalah sebagai berikut :

a. Direktorat teknis menyampaikan daftar penerima KIP yang tercantum dalam surat keputusan direktur ke lembaga penyalur untuk dibuatkan rekening.

b. Direktorat teknis mengajukan Surat Permintaan Pembayaran (SPP) dan Surat Perintah Membayar (SPM) ke KPPN untuk diterbitkan SP2D ke rekening penyalur atas nama direktorat teknis di lembaga penyalur.

c. Direktorat teknis menyampaikan Surat Perintah Pemindah bukuan (SP2N) kepada lembaga penyalur untuk menyalurkan dana dari rekening penyalur ke rekening penerima.

d. Direktorat teknis menginformasikan daftar siswa penerima kepada dinas pendidikan kabupaten/kota dengan melampirkan surat keputusan penerima.

e. Penyaluran dana KIP kepada peserta didik penerima dilakukan melalui Tabungan $\mathrm{Ku}$ atau virtual account.

f. Pengambilan/pencairan dana KIP dilakukan oleh peserta didik penerima di lembaga penyalur dengan ketentuan : 1) Menunjukkan surat keterangan kepala sekolah/ketua lembaga, 2) Fotocopi lembar rapor yang berisi bio data, lengkap dengan nama sekolah, NPSN dan NISN, dan 3) KTP orang tua/wali.Mekanisme Penetapan dan penyaluran Kartu dengan kNPKTP orang.

\section{METODE PENELITIAN}

Metode penelitian yang digunakan dalam penelitian ini adalah penelitian kepustakaan (library research) dan penelitian lapangan (field research). Sedangkan tipe dan pendekatan yang digunakan adalah pendekatan deskriptif kualitatif. Sumber data yang digunakan adalah data primer dan data sekunder. Data primer diperoleh dari informan yang terkait, yaitu : kepala sekolah, tenaga tata usaha sekolah, guru yang ditunjuk mengelola/mengurus KIP, siswa penerima dana KIP dan orang tuanya di SMP Negeri 3 Banjarbaru. Sedangkan data sekunder diperoleh dari dokumen atau arsip yang terkait dengan obyek penelitian. Teknik pengumpulan data yang digunakan adalah teknik wawancara, teknik observasi, dan teknik dokumentasi. Selanjutnya data yang terkumpul dilakukan kajian atau analisis secara kualitatif, dengan melakukan reduksi data, display data, dan penarikan kesimpulan-kesimpulan dengan cara merujuk pada teori-teori dan norma yang relevan, terutama Peeraturan Direktur Jendral Pendidikan Dasar dan Menengah Nomor : 1881 / D / BP / 2019 tentang Petunjuk Pelaksanaan Program Indonesia Pintar pada Jenjang Pendidikan Dasar dan Menengah.

\section{HASIL DAN PEMBAHASAN}

Berdasarkan data hasil penelitian yang telah dilakukan, bahwa Implementasi Kebijakan Kartu Indonesia Pintar di SMPN 3 Banjarabaru tahun

22 | Tamliha Harun | Impelementasi Program...... 
pelajaran 2019/2020, dapat dipaparkan sebagai berikut :

\section{Pengelolaan KIP di Sekolah}

a. Pada prinsipnya pengelolaan dana KIP di sekolah ini sudah berjalan sesuai dengan ketentuan Peeraturan Direktur Jendral Pendidikan Dasar dan Menengah Nomor : 1881 / D / BP / 2019 tentang Petunjuk Pelaksanaan Program Indonesia Pintar pada Jenjang Pendidikan Dasar dan Menengah.

b. Dalam mengimplementasikan kebijakan Program Indonesia Pintar (KIP), kepala sekolah menunjuk dan menetapkan guru tertentu sebagai koordinator dengan surat keputusan kepala sekolah.

c. Guru koordinator ini bertugas mengelola dana KIP yang ada di sekolah.

d. Guru koordinator pengelola KIP ini bertugas, antara lain :

1) Melakukan sosialisasi tentang kebijakan KIP kepada siswa dan walinya sebanyak dua kali. Yang pertama pada awal tahun ajaran baru, dan yang kedua pada saat setelah nama siswa ditetapkan sebagai penerima KIP. Pada sosialisasi yang kedua ini materi sosialisasi yang disampaikan lebih bersifat teknis, yaitu tentang siapa-siapa saja siswa yang berhak menerima dana KIP, digunakan untuk apa saja oleh siswa dana KIP tersebut, bagaimana cara mendapatkan dan mencairkan dana Kip tersebut, dan lain sebagainya.

2) Menyeleksi siswa calon penerima KIP berdasarkan kepemilikan Kartu Perlindungan Sosial (KPS), Pemegang Keluarga Harapan (PKH), dan siswa yang statusnya yatim, atau yatim piatu.

3) Mengumpulkan,merekapitulasi, dan memverifikasi KIP yang dikumpul siswa calon penerima ke sekolah untuk di input ke Data Pokok Pendidikan (Dapodik) agar bisa diusulkan sebagai siswa penerima dana KIP secara online.

\section{Mekanisme Penyaluran Kartu Indonesia Pintar (KIP) di Sekolah}

Mekanisme pengusulan KIP dimulai dari guru koordinator yang ditugaskan sebagai pengelola Kartu Indonesia Pintar pada SMPN 3 Banjarbaru, dengan melakukan pengumpulan dan rekapitulasi sekaligus memverifikasi Kartu Indonesia Pintar yang sudah diserahkan oleh siswa kemudian dicocokan dengan keadaan siswa yang sebenarnya sesuai dengan kriteria yang sudah ditetapkan. Kartu Indonesia Pintar tersebut di input melalui data pokok pendidkan ( Dapodik ) sebagai idintitas siswa pemegang KIP. Pada tahun 2019 siswa yang mendapatkan dan membawa Kartu Indonesia Pintar sebanyak 228 siswa.

Mekanisme selanjutnya adalah mengirim data. Data yang telah diverifikasi dan direkapitulasi oleh pihak sekolah diserahkan ke dinas Pendidikan Kota Banjarbaru. Bersamaan dengan itu pihak sekolah juga menginput data siswa yang telah mendapatkan Kartu Indonesia Pintar pada Dapodik sekolah melalui Operator Dapodik. Penetapan siswa penerima KIP dan Pencairan dana dilaksanakan oleh pusat. Peran sekolah dimulai kembali setelah terbitnya Surat Keputusan ( SK ) siswa penerima KIP yang dikeluarkan oleh Kementrian Pendidikan dan Kebudayaan.

Pencairan dana KIP bagi siswa SMPN 3 Banjarbaru di kirim langsung melalui Bank yaitu Bank Rakyat Indonesia. Pengambilan dana dilakukan setelah turunya Surat Keputusan (SK) dari Direktorat Jendaral Pendidikan Dasar dan Menengah Kementerian Pendidikan dan Kebudayaan yang berisi daftar nama siswa penerima KIP yang dikirim ke Dinas Pendidikan Kota Banjarbaru. Kemudian Dinas Pendidikan Kota Banjarbaru mengirim SK Dirjen Dikdasmen tersebut ke sekolah untuk di beritahukan kepada siswa penerima dana KIP. Selanjutnya setiap siswa penerima KIP melakukan pembukaan rekening pada BRI yang telah ditentukan dengan membawa Surat Keterangan dari Sekolah yang berisi Nomor Vatual Acount masing-masing yang tertera pada Daftar nama siswa penerima KIP.

\section{Beberapa Faktor Kendala dalam Implementasi KIP di Sekolah}

Pada prinsipnya implementasi KIP di SMPN 3 Banjarbaru sudah berjalan lancar sesuai dengan ketentuan dan harapan. Walaupun demikian dalam pelaksanaannya masih ditemukan beberapa kendala, sebagai berikut :

a. Karena Kementerian Pendidikan dan Kebudayaan selalu melakukan evaluasi 
terhadap program Kartu Indonesia Pintar pada setiap periode untuk penyempurnaan program KIP, menyebabkan terjadinya perubahan -perubahan mekanismenya implementasinya, Sehingga membuat para pelaksana di sekolah harus memahami terhadap makanisme baru tersebut di setiap periode. Terkadang pelaksana merasa kebingungan dengan adanya perubahan mekanisme yang baru tersebut.

b. Banyak siswa penerima dana KIP dan walinya kurang memahami tujuan dan untuk apa bantuan dana KIP tersebut diberikan kepada mereka, sehingga dana KIP yang diterima sering digunakan tidak sesuai dengan ketentuan yang sudah ditetapkan, yaitu untuk membiayai keperluan siswa penerima di luar biaya penunjang pendidikan mereka.

Sulitnya mengumpulkan kwitasi/tanda bukti penggunaan dana KIP oleh siswa, untuk dijadikan sebagai bahan pengawasan apakah dana KIP yang diterima siswa penerima tersebut benar benar dipergunakan sesuai ketentuan untuk menunjang keperluan dan peralatan sekolah mereka.

\section{KESIMPULAN}

Berdasarkan hasil penelitian dan pembaasan yang telah dilakukan, maka dapat dibuat kesimpulan sebagai berikut :

1. Implementasi Program Indonesia Pintar (PIH), melalui Kartu Indonesia Pintar (KIP) pada SMPN 3 Banjarbaru sudah berjalan dengan baik dan efektif, sesuai dengan Peraturan Direktur Jenderal Dikdasmen Kementerian Pendidikan dan Kebudayaan Nomor : 1884/D/BP/2019 tentang Petunjuk Pelaksanaan Program Indonesia Pintar pada Jenjang Dikdasmen.

2. Siswa penerima bantuan Program Indonesia Pintar melalui Kartu Indonesia Pintar di SMPN 3 Banjarbaru berjumlah 228 siswa yang seluruhnya memiliki Kartu Indonesia Pintar. Siswa-siswa penerima dana KIP tersebut telah memenuhi persyaratan dan ketentuan. Namun demikian, dari 228 siswa penerima dana KIP tersebut, ada beberapa orang yang sudah tidak memenuhi persyaratan, disebabkan pendapatan orang tua/wali siswa yang bersangkutan sudah meningkat dari sebelumnya, Namun mereka tidak bersedia untuk mengundurkan diri sebagai penerima dana KIP.
3. Pengelolaan dan mekanisme implementasi Program Indonesia Pintar (PIP), melalui Kartu Indonesia Pintar (KIP) di SMPN 3 Banjarbaru sudah berjalan sesuai dengan ketentuan, baik dari proses penunjukan dan penetapan guru koordinator KIP, proses pelaksanaan tahapan-tahapan sosialisasi KIP, proses seleksi calon siswa penerima KIP, proses rekapitulasi, verifikasi dan penginputan data siswa calon penerima KIP ke Dapodik, sampai pencairan dan penggunaan dana KIP oleh siswa penerima.

4. Dengan di implentasikannya Program Indonesia Pintar (PIH), melalui Kartu Indonesia Pintar (KIP) pada SMPN 3 Banjarbaru sangat dirasakan banyak memberi manfaat bagi siswa-siswa dari keluarga miskin atau kurang mampu, antara lain : mereka dapat mengikuti dan melanjutkan pendidikannya dengan baik dan lancar di sekolah, sehingga jumlah angka siswa putus sekolah dapat ditekan.

5. Walaupun demikian, masih ada ditemukan sebagian siswa penerima KIP atau walinya kurang memahami dalam penggunaan dana KIP, sehingga digunakan untuk membiayai pengeluaran di luar konteks keperluan pendidikaan/sekolahnya.

\section{REFERENSI}

Islamy, M. Irfan, 1999, Kebijakan Publik (Modul), Universitas Terbuka, Jakarta.

Lembaga Administrasi (LAN), 1997, Sistem Administrasi Negara RI, PT. Toko Gunung Agung, Jakarta.

MPR RI, 2017, Undang-Undang Dasar Negara RI Tahun 1945, Sekretariat Jenderal MPR RI, Jakarta.

Nugroho, Riant, 2011, Public Policy (Dinamika Kebijakan-Analisis Kebijakan-Manajemen Kebijakan), PT. Elex Media Komputindo, Jakarta.

Pemerintah Indonesia, 2019, Peraturan Direktorat Jendral Pendidikan Dasar dan Menengah No. 1881 / D / BP/ 2019 Tentang Petunjuk Pelaksanaan Program Indonesia Pintar, Sekretariat Negara, Jakarta.

Rawita, Ino Sutisno, 2010, Kebijakan Pendidikan (Teori, Implementasi dan Monev), Kurnia Kalam semesta, Yogyakarta.

Sugiano, 2010, Metode Penelitian Administrasi, Alfabeta, Bandung. 